\title{
Sliding Mode Control Compared to PID Control Applied for a 4 Cables Parallel Robot
}

\author{
Fouad Inel ${ }^{1}$ \\ ${ }^{1}$ Mechanical engineering department, university of skikda - Algeria \\ inelfouad@yahoo.fr
}

\begin{abstract}
This paper present a study the performance of sliding mode controller (SM) against PID controller, this last SM control algorithm is based to provide the stability of the endeffecter and a PIDC is classical proportional integrated derivative controller. The aim contribution of this work is in the firstly, the graphical user interface witch present a point to point command and the visualization of end-effector position parameters, secondly present the dynamic model for our mechanism and mathematics equations for the two control techniques SM and PID .Moreover, the performances concern settling time, precision, vibration and system stability for each controller during trajectory tracking. Finally, to confirm the validity of the performance between the both controls, some simulation results are done for the different trajectories.
\end{abstract}

Keywords: Cables parallel robot, sliding mode control, PID control, dynamic model, GUI

\section{Introduction}

In recent years, robots have made tremendous inroads into industries for manufacturing and assembly. However, for long reach robotics such as inspection and repair in shipyards and airplane hangars, application of robotics is still in its infancy. Conventional robots with serial or parallel structures are impractical for these applications since the workspace requirements are higher than what the conventional robots can provide. For these reasons, cables-driven robots have received attention and have been recently studied [1]. The cable parallel robot are a special class of parallel mechanisms, whose trusts consist of cables whose lengths are adjustable to control the end-effector's position and orientation [2], this last is a fully parallel mechanism in closed chains with $\mathrm{n}$ degrees of freedom for the end effector; this last is connected to fixed platform by $\mathrm{m}$ cables; and each cable connects an output point attached to the fixed based of the robot to the mobile platform.

These robots have few moving parts, with reduced mass, and are most suitable for tasks required high performance such as speed and accuracy and provide a large workspace [3]. By moving the cables connections points, it also has a work space much more grace to rolling cables, which allow the effector to be very far from its base, and reduce the distance near zero with very high acceleration, and the main advantage of the cable are; a larger workspace for the same overall dimension of the robot; light weight cables resulting in very safe an transportable system [4]. The best-known is control of cameras in stadiums (Skycam), this application is moved a fixed camera on a moving platform, another field of interest in biomedical application is the monitoring of the movement. An example may be mentioned CaTraSys (Cassino Tracking System) was used for identifying kinematic parameters and the mobility of man. Also, rehabilitation applications transport [5], the main disadvantages of parallel manipulators lie in the nature

Received (April 21, 2017), Review Result (December 5, 2017), Accepted (December 12, 2017) 
of the cables suffer from unidirectional constraints that can only be pulled and not pushed. In this variant of robots, the cables must be with the tension in the whole workspace [6].

This paper is organized as follow: the structure of the our parallel robot with 4 cables. Next, we present the demonstration of geometric and dynamic models and we present a graphical user interface for the point to point command, finally, presents the controls modeling and some simulation results for different tests.

\section{Structure of 4 Cables Parallel Robot}

In Figures 1 shows the general structure of our robot which consist mainly of a fixed base, a moving platform that holds the end effector, a set of parallel cables connecting to the moving platform at the base and a set of motorized pulleys.

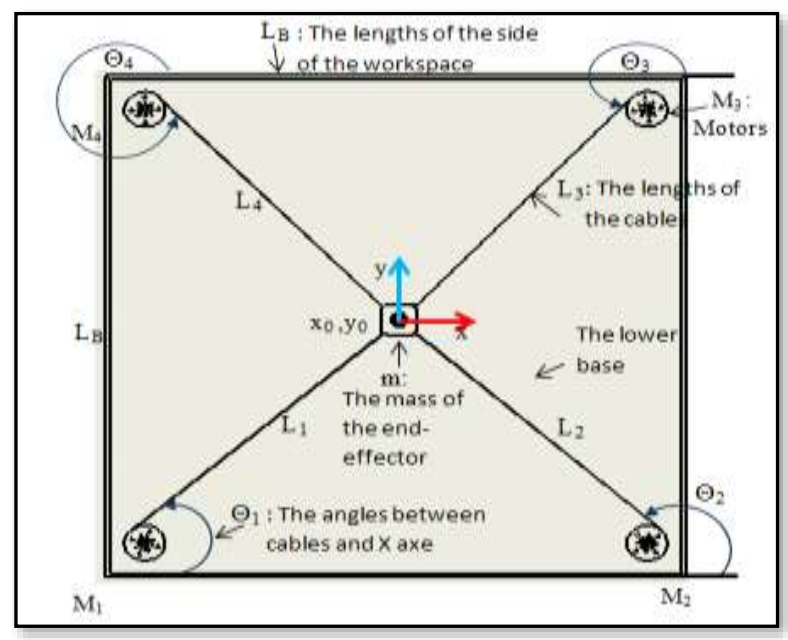

Figure 1. The General Structure of Robot with 4 Cables

\section{Modeling}

To analyze the movement of the end effector, we need to take into account some characteristics of the motor, the pulleys and the cables [7,8 and 9]. Therefore, dynamic equations are expressed by the following relationship:

$$
M(X) \ddot{X}+N(X, \dot{X})=S(X) \tau
$$

Where:

$X=\left(\begin{array}{l}x \\ y\end{array}\right):$ is the position vector of the end effector.

The dynamic model of the motor is represented in the following figure: 


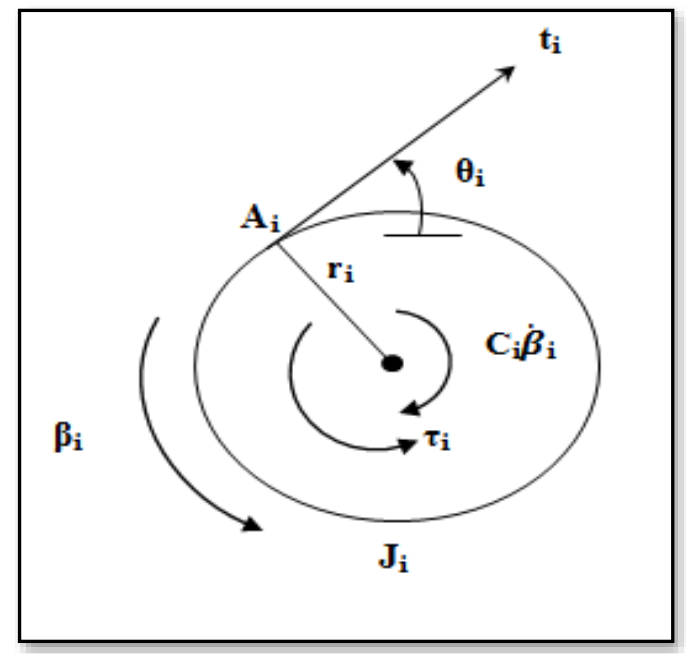

Figure 2. The Structure Diagram the Pulley /Shaft

Where :

$$
\begin{aligned}
& J \ddot{\beta}+C \dot{\beta}=\tau-r t . \\
& J=\left(\begin{array}{cccc}
J_{1} & 0 & 0 & 0 \\
0 & J_{2} & 0 & 0 \\
0 & 0 & J_{3} & 0 \\
0 & 0 & 0 & J_{4}
\end{array}\right) \text {, and } C=\left(\begin{array}{cccc}
C_{1} & 0 & 0 & 0 \\
0 & C_{2} & 0 & 0 \\
0 & 0 & C_{3} & 0 \\
0 & 0 & 0 & C_{4}
\end{array}\right)
\end{aligned}
$$

We consider that all the rays of the pulley are the same:

$\mathrm{ri}=\mathrm{r}(\mathrm{i}=1.2 \ldots 4)$.

$\tau\left(\tau_{1} \cdot \tau_{2}, \ldots \tau_{i}\right)^{T}$ :is the vector of the torques applied by the motors.

$\mathrm{t}(\mathrm{t} 1, \mathrm{t} 2, \ldots \mathrm{ti})^{\mathrm{T}}:$ is the vector of tension cables.

$\beta$ :is the angle of rotation of the pulley.

So:

$$
\begin{gathered}
t=\frac{1}{r}(\tau-J \ddot{\beta}-C \dot{\beta}) \\
\beta=\left(\begin{array}{l}
\beta_{1}(X) \\
\beta_{2}(X) \\
\vdots \\
\beta i(X)
\end{array}\right)=\frac{1}{r}\left(\begin{array}{l}
L_{10}-L_{1} \\
L_{20}-L_{2} \\
\vdots \\
L_{i 0}-L_{i}
\end{array}\right)
\end{gathered}
$$

Finally, the set of equations of the dynamic model can be expressed in a standard form for robotic systems (5):

$$
\ddot{X}(t)=M^{-1}(X) * N(X, \dot{X})+M^{-1}(X) * S(X) * \tau
$$

To present the dynamical model in the state space representation, we introduce the state variables:

equations (5) can be expressed as follows: 


$$
\Rightarrow\left\{\begin{array}{l}
\dot{x}_{12 d}(t)=x_{22 d}(t) \\
M_{11} \dot{x}_{22 d}(t)+M_{12} \dot{x}_{42 d}(t)=u_{1}(t)-N_{11} x_{22 d}(t)-N_{12} x_{42 d}(t) \\
\dot{x}_{3}(t)=x_{4}(t) \\
M_{21} \dot{x}_{22 d}(t)+M_{22} \dot{x}_{42 d}(t)=u_{2}(t)-N_{21} x_{22 d}(t)-N_{22} x_{42 d}(t)
\end{array}\right.
$$

\section{Control Methods}

In this section, two control methods are proposed and explained in detail which is SMC and PIDC.

\subsection{Sliding Mode Controller}

A sliding mode control which is a nonlinear feedback control with variable structure. The main advantage of sliding mode control is that the system is insensitive to extraneous disturbance and internal parameter variations while the trajectories are on the switching surface. [10]

In variable structure control with Sliding mode, the system structure is switched and the system state crosses the predetermined hyper-plane, so that the system slides along the reference trajectory. The following equations show how to calculate the sliding Surface [11].

The representation status of our robot results in a system of nonlinear coupled equations:

$$
\dot{X}_{2 d}(t)=f\left(X, X_{2 d}\right)+g\left(X, X_{2 d}\right) * U(t)
$$

The sliding surface along $\mathrm{x}$ and $\mathrm{y}$ can be expressed as:

$$
\begin{aligned}
& s_{2 d x}=C_{12 d x} *\left(x_{12 d}(t)-x_{r e f}\right)+C_{22 d x} * x_{22 d}(t) \\
& s_{2 d y}=C_{12 d y} *\left(x_{22 d}(t)-y_{r e f}\right)+C_{22 d y} * x_{42 d}(t)
\end{aligned}
$$

$\mathrm{C} 12 \mathrm{dx}, \mathrm{C} 22 \mathrm{dx}, \mathrm{C} 12 \mathrm{dy}$ et $\mathrm{C} 22 \mathrm{dy}$ : are parameters determined by simulation.

$x_{\text {ref }}$ and $y_{\text {ref }}$ : are the desired (reference parameters) according $\mathrm{x}$ and $\mathrm{y}$.

$$
\begin{array}{r}
\dot{x}_{22 d}(t)=\frac{\alpha_{1} * x_{22 d}(t)+\alpha_{2} * x_{42 d}(t)}{\beta i}+\frac{M_{22} * u_{1}(t)-M_{12} * u_{2}(t)}{\beta i} \\
\dot{x}_{42 d}(t)=-\frac{\rho_{1} * x_{22 d}(t)+\rho_{2} * x_{42 d}(t)+M_{21} * u_{1}(t)-M_{11} * u_{2}(t)}{\beta i}
\end{array}
$$

So to determine the order of law we worked with a new synthesis method that is the approach to the finish law [12].

$$
\begin{aligned}
& \dot{\boldsymbol{s}}_{2 d x}=-K_{2 d x} s_{2 d x}-Q_{2 d x} \operatorname{sign}\left(s_{2 d x}\right) \\
& \dot{\boldsymbol{s}}_{2 d y}=-K_{2 d y} s_{2 d y}-Q_{2 d y} \operatorname{sign}\left(s_{2 d y}\right)
\end{aligned}
$$

With :

$K 2 d x, Q 2 d x, K 2 d y, Q 2 d y$,: are parameters determined by simulation.

$\operatorname{Sign}(\operatorname{S} 2 d x)$ and $\operatorname{Sign}(S 2 d y)$ : is de sign of surface $(+1$ or -1$)$.

The combination of equation (7), (8) and (11) we found that: 


$$
u_{2 d x}(t)=-K_{12 d x} * x_{22 d}(t)-\sigma_{x} x_{42 d}(t)-K_{22 d x} *\left(x_{12 d}(t)-x_{1 r e f}\right)-Q_{x} \operatorname{sign}\left(s_{2 d x}\right)
$$

with the same method applied on $\mathrm{x}$ we applied on $\mathrm{y}$ we find that:

$$
u_{2 d y}(t)=-K_{12 d y} * x_{42 d}(t)-\sigma_{y} x_{22 d}(t)-K_{22 d y} *\left(x_{32 d}(t)-x_{2 r e f}\right)-Q_{y} \operatorname{sign}\left(s_{2 d y}\right)
$$

\subsection{PID Controller}

The implementation of a Proportional-Integrated and Derivative controller based on the overall system Cartesian dynamics equations which motion in (5) [13].In this Paper the PID controller gains are determined the error using a Matlab program simulation to achieve reasonable performance for a different trajectories and their cables lengths necessary. The establishment of the control law along $\mathrm{x}$ along $\mathrm{y}$ is:

$$
\left\{\begin{array}{l}
U_{X}=K_{P} e_{X}(t)+K_{I} \sum_{i=1}^{n-1} e_{X}+K_{D} \dot{e}_{X}(t) \\
U_{Y}=K_{P} e_{Y}(t)+K_{I} \sum_{i=1}^{n-1} e_{Y}+K_{D} \dot{e}_{Y}(t)
\end{array}\right.
$$

This equation $\mathrm{U}(\mathrm{t})$ along $\mathrm{X}$ and $\mathrm{Y}$ represent the command vector of the cable-based robot for applying adequate electrical voltages to the motors in order to generate tensions on the cables. The algorithm of the controls in closed-loop case is shown in Figure 3.

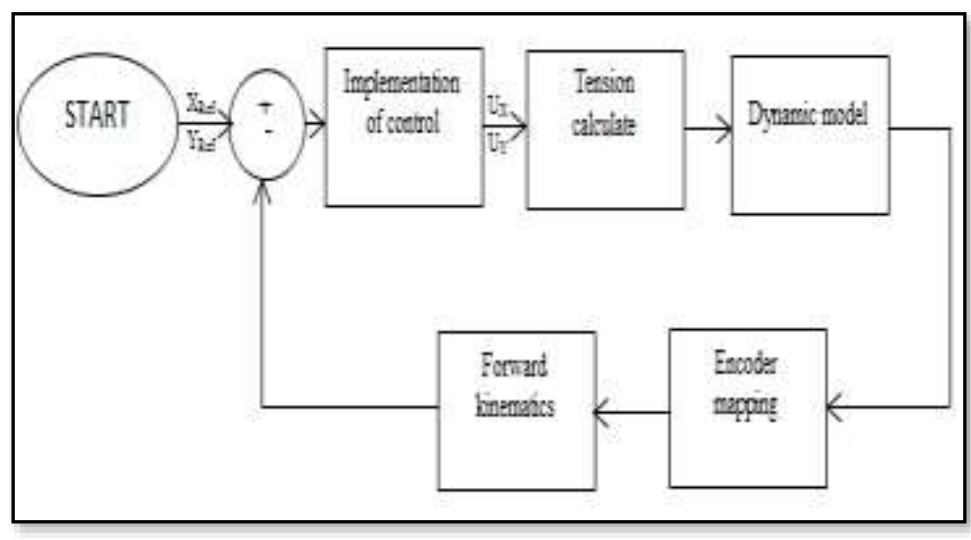

Figure 3. A Flow-Chart of the Controls Algorithm

\section{Graphical User Interface (GUI)}

In this section we present a graphical interface for the 4 cables parallel robot; these last it composed three parts: the upper part shows the simulator of the virtual cables based robot with matlab software and the second part shows the virtual picture of homemade prototype of 4 cable-parallel robot used solidworks software and the lower part shows the trajectory of the end effector for the three tests Figure 4. 


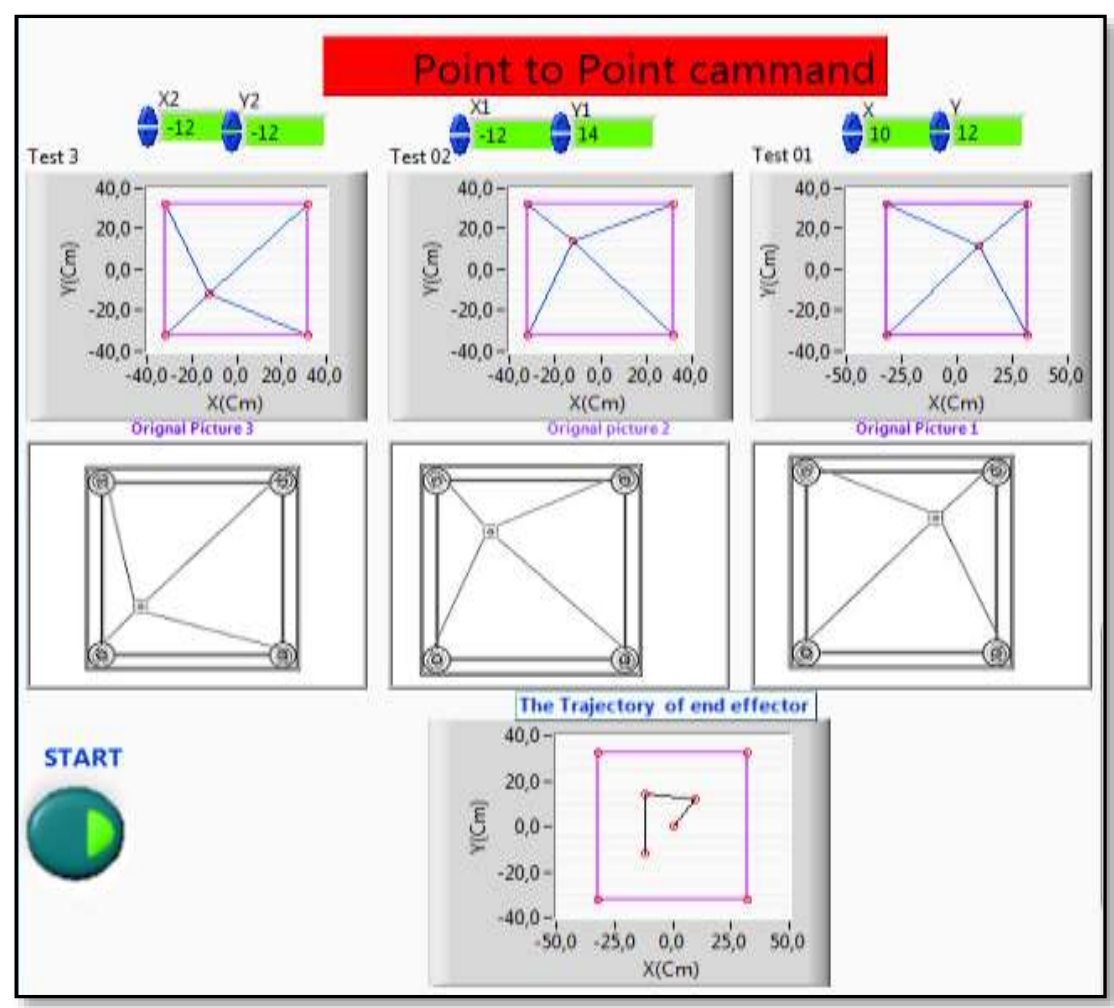

Figure 4. Example of a Point to Point Command for a Robot with 4 Cables

Figure 5 shows the initialization of the graphical user interface (initial case).

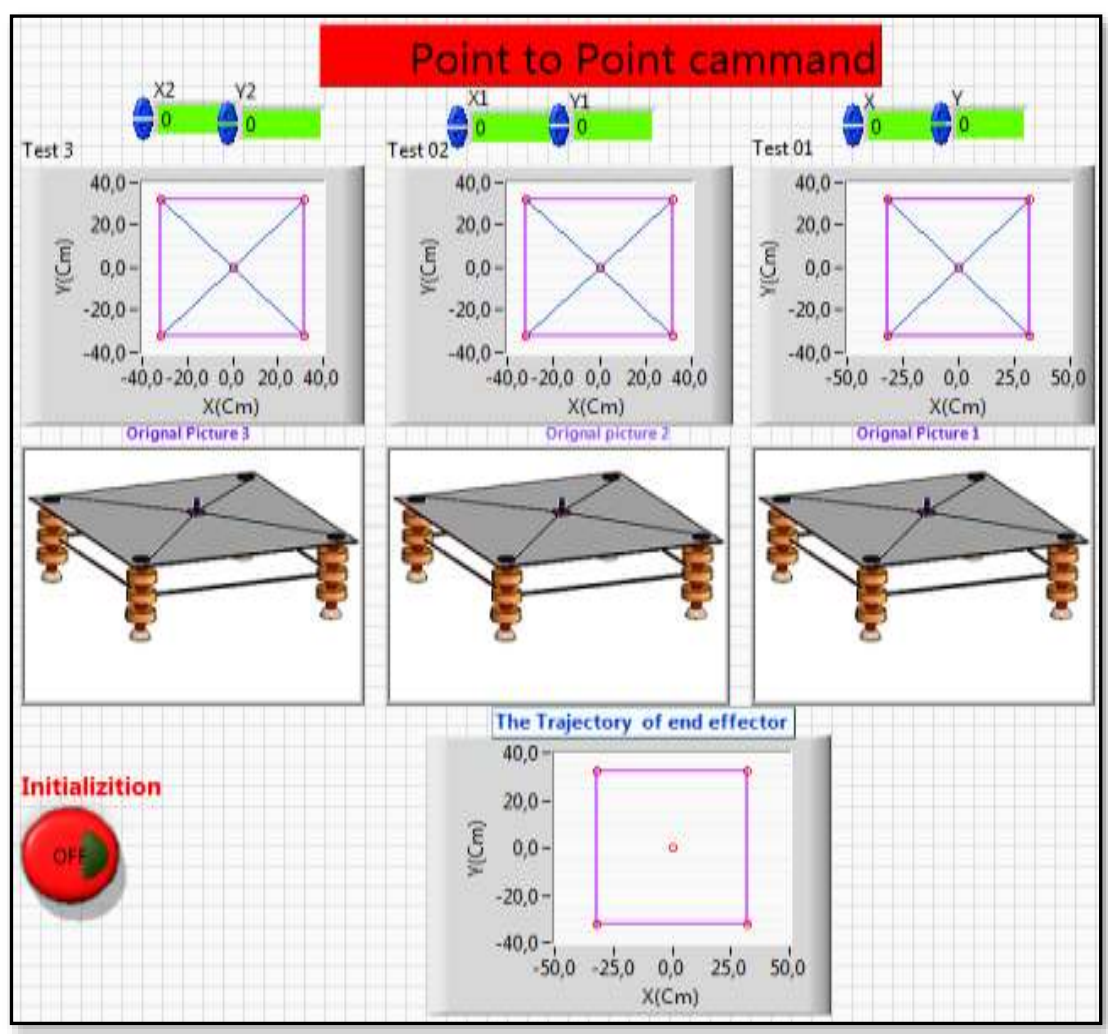

Figure 5. The Initialization of a Graphical User Interface (Initial Case) 


\section{Simulation Results}

In this part we present the simulation of the response of four cables parallel robot which has a non-linear equation system, for this purpose, we use the $4^{\text {th }}$ order Runge Kutta solver as a numeric solution for linear the system and we then implement a Cartesian of the two control methods; sliding mode and PID.

In our system, we do not have direct access to Cartesian position of the end-effector, instead, we get the direct measurements of the rotation angles $\beta \mathrm{i}$ of the pulleys, then these values are converted into the cable lengths $\mathrm{L}_{\mathrm{i}}$, these lengths are then used as inputs to the forward kinematics to obtain the Cartesian position X and Y. [14,15].

The parameters for the dynamics equations of motion (9) for a parallel robot with 4 cables are:

\section{Table 1. Initial Parameters for the Dynamics Equation}

\begin{tabular}{|l|l|l|}
\hline Variables & Initial Value & Unit \\
\hline point mass $\mathbf{m}$ & 0.01 & $\mathrm{Kg}$ \\
\hline The base square side is Lb & 0.6580 & $\mathrm{~m}$ \\
\hline $\begin{array}{l}\text { shaft rotational viscous damping } \\
\text { coefficients Ci }(\mathrm{i}=1: 4)\end{array}$ & 0.01 & $\mathrm{Nms}$ \\
\hline Rotational shaft/pulley inertias Ji & 0.0008 & $\mathrm{kgm}^{2}$ \\
\hline The rays of the pulley ri $(1,2,3,4)$ & 1.5 & $\mathrm{~cm}$ \\
\hline The cable lengths $\mathbf{L i}(1,2,3,4)$ & 0.465 & $\mathrm{~m}$ \\
\hline
\end{tabular}

The following parameters values that provides an acceptable compromise on performances have been selected by manual trials about errors compared $\mathrm{X}$ and $\mathrm{Y}$ for our SMC and PIDC: are C12dx=55000; C22dx=150; K2dx=150; Q2dx=100; C12dy=55000; $\mathrm{C} 22 \mathrm{dy}=150 ; \mathrm{K} 2 \mathrm{dy}=150$; $\mathrm{Q} 2 \mathrm{dy}=100$, and the values of coefficient for PID control are: $\mathrm{Kp}=2500, \mathrm{Kd}=100$ and $\mathrm{Ki}=0,7$. So we put the reference of our system in the center of the workspace $(0,0)$.

Figure (6) and Figure (7) show the simulation results of dynamic model with SM controller for the circular trajectory and the change of values tensions to trace this trajectory. Figure (8) and Figure (9) present also th simulation results of dynamic model with PID controller for the circular trajectory and the variations tensions applied for the cables. Figure (10) and Figure (11) present. The performance response comparison between SMc and PIDc and The error of precision between the reference path and the real paths of the both controls. 


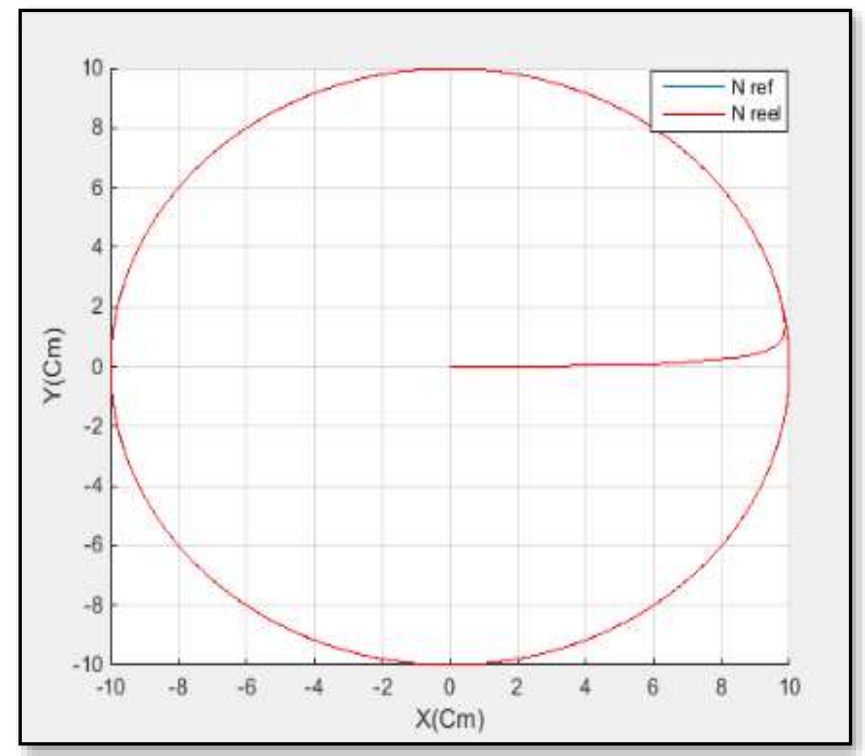

Figure 6. Test the Tracking of Circular Trajectory with SMC without Work Space

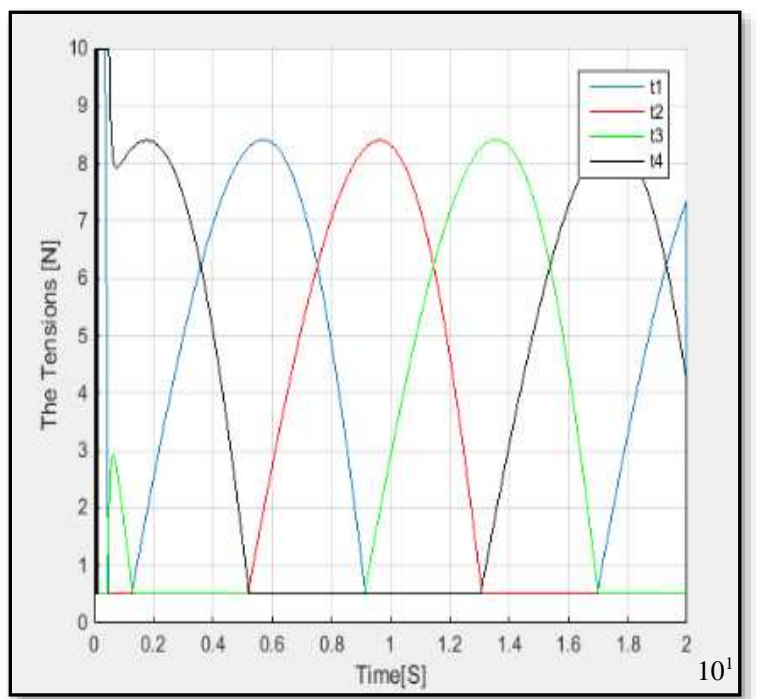

Figure 7. The Tensions Applied on the Cables to Trace A Circular Trajectory 


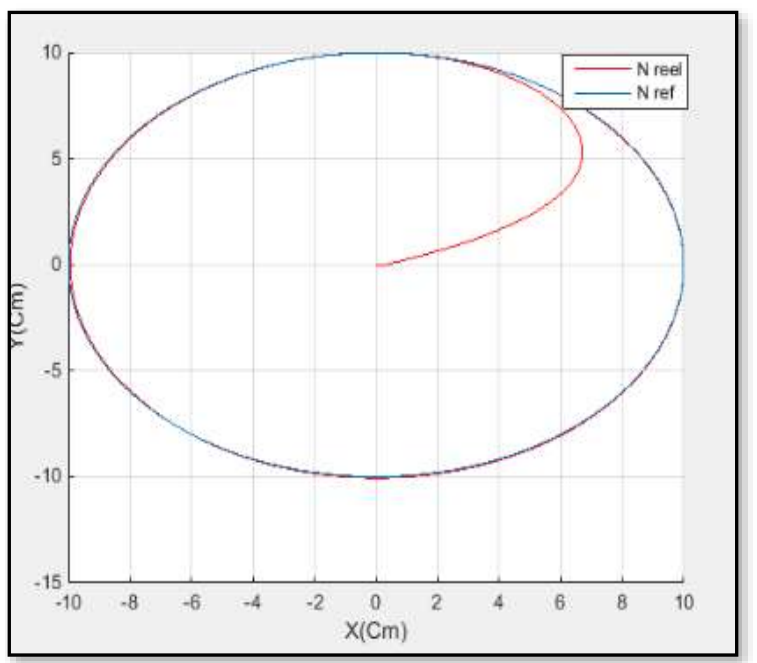

Figure 8. Plot the Tracking Circular Trajectory with PID Controller

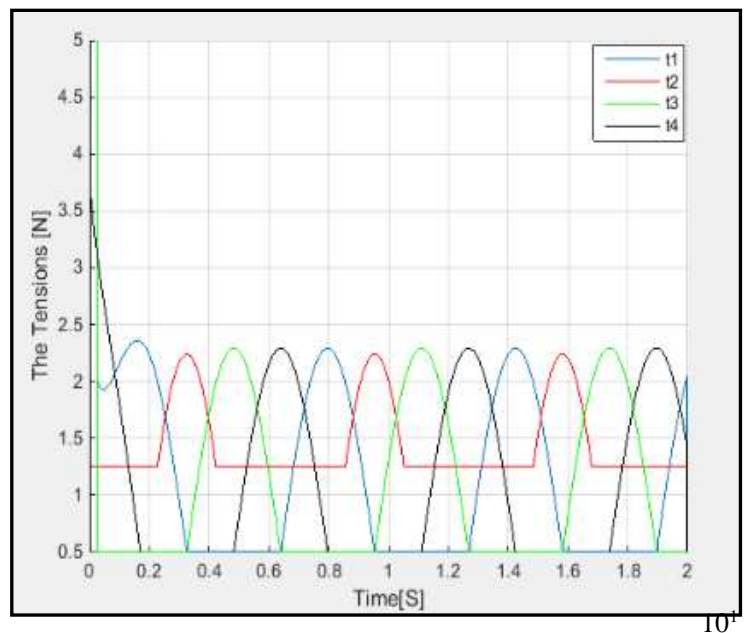

Figure 9. The Change of the Tensions Applied For the Cables

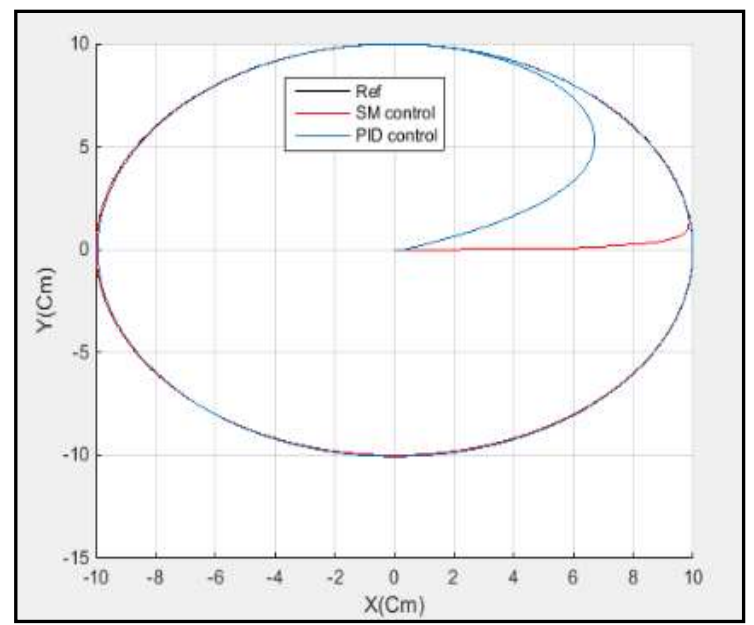

Figure 10. The Performance Response Comparison between SMc and PIDc 


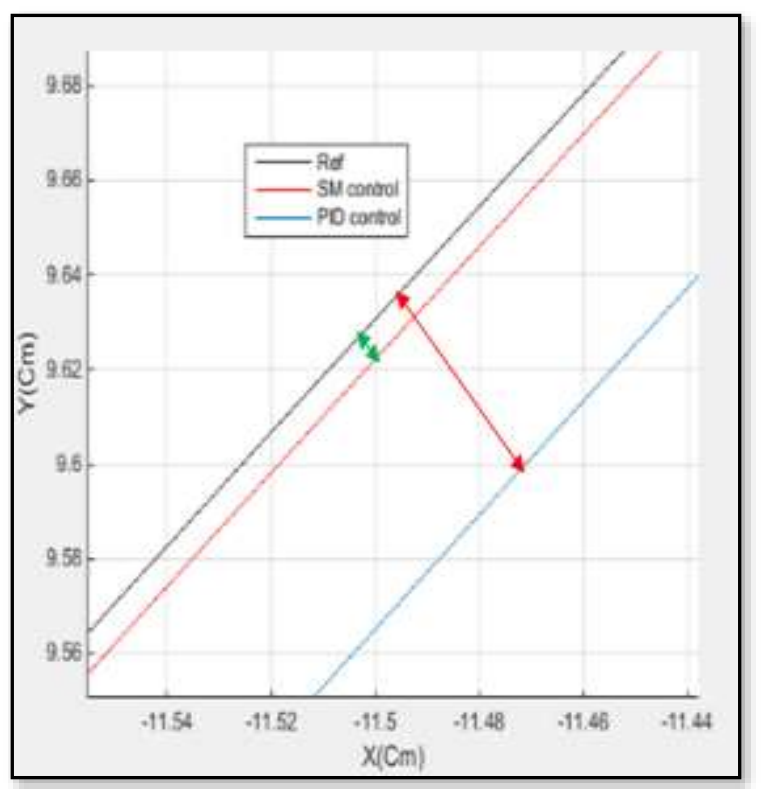

\section{Figure 11. The Error of Precision between the Ref Path and the Real Paths of the Two Control Methods}

An illustrative example of comparison is given in Figure 12 where we can distinguish the responses of SMC and PDC to sinusoidal input, we obtained a stable system with arise time of $5 \mathrm{~s}$ with SMc and 3s for PIDc.

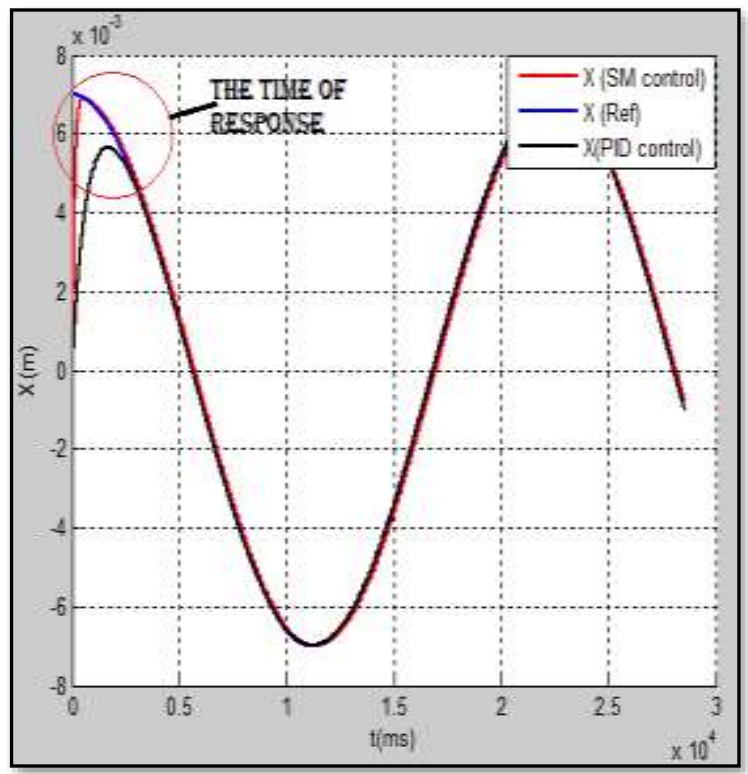

Figure 12. The Time Response of SMC and PDC to a Sinusoidal Input

After analyzing the results for both controllers we find that; the two control methods can tracking the reference trajectory, but sliding mode give better performance time (very fast) to follow the desired path (with reference to simulation curves Figure 10 and 12), and the error between the desired and a real paths for sliding mode superimposed with high precision we reference with Figure 11 (red arrow between desired path and a real path with PID control and the green arrow between desired path and a real path with SM 
control) ; so we note that the sliding mode is robust control to gives a good performance efficiency for the stability.

Also we note with respect to the tensions that, the motors with PID control consume more energy than with SM control (with reference to simulation curves Figure 7 and 9) to follow a predefined path.

To illustrate the performance of the two controllers, also we compare the tracking of two triangular paths Figures 13( $a$ and $b$ ) and 14( $a$ and $b$ ), with high speed velocity ( $w=20$ $\mathrm{rad} / \mathrm{sec})$.

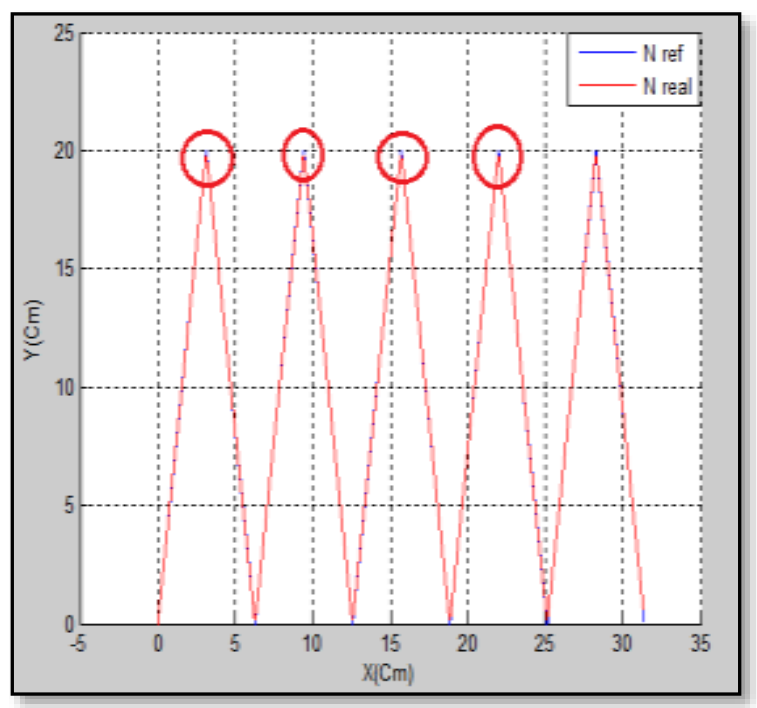

A) Plot of the End-Effector Position in X-Y Plane

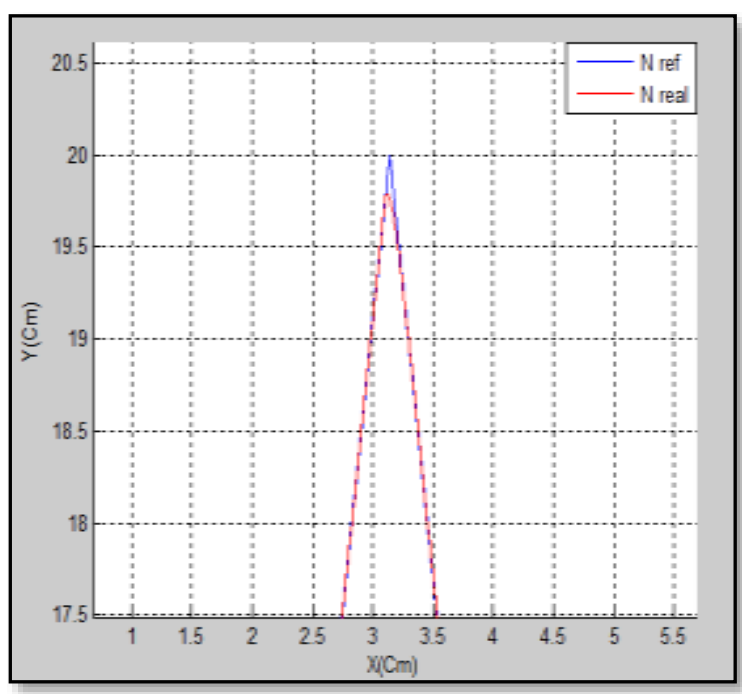

B) A Zoom View of Plot a

Figure 13. The Tracking of a Triangular Trajectory with SM Control 


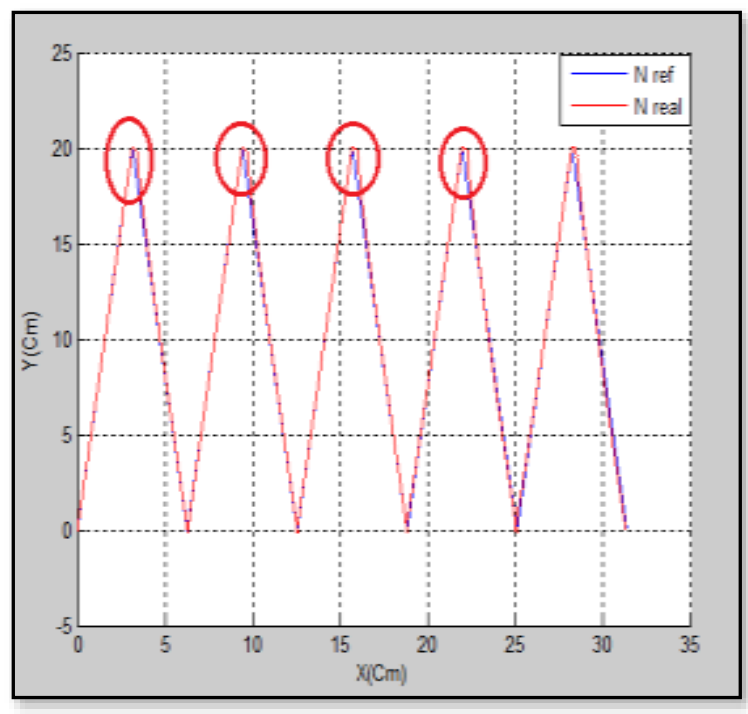

A) Plot of the End-Effector Position in X-Y Plane

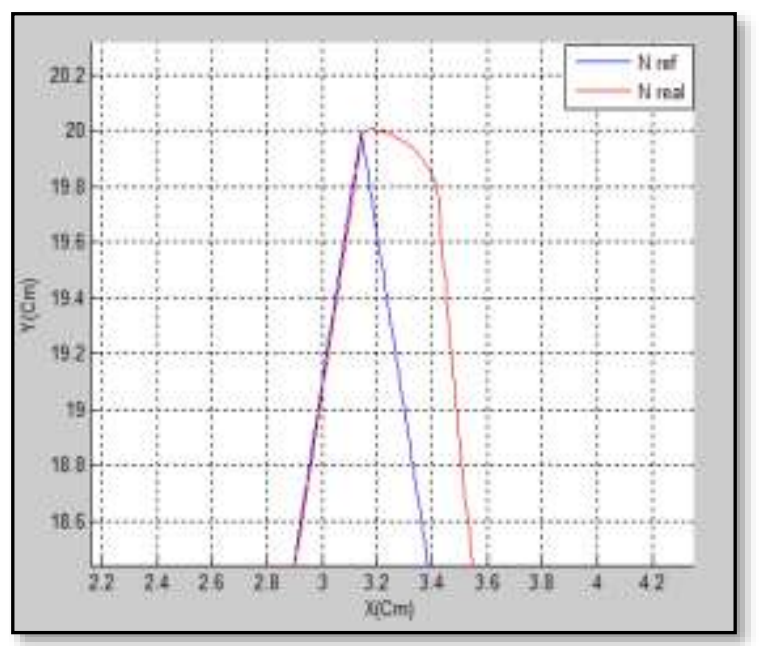

B) A Zoom View of Plot $A$

\section{Figure 13. The Tracking of a Triangular Trajectory with PID Control}

We notice that the tracking process of Figure 13(a) was successfully performed than the Figure 14(a), also we can say that the SM controller is very fast to tracking the desired path and can maintains the error value between the real and desired paths even high speed, but the PID control can't resist especially with high speed.

\section{Conclusions}

This paper addressed the issue of controlling and simulation of parallel robot with four cables, these last; the control techniques based on SMc and PIDc. In addition, this paper presented a graphical user interface for the point to point command based on dynamic model, by using the labview software, moreover, numerical simulations have been carried out by developing a specific code which includes a graphical user interface for a user-friendly real time visualization of end-effector position as well as modification of the system parameters. The tensions should always be positive and be contained between $\mathrm{T}_{\min }$ and $\mathrm{T}_{\max }$, also the cables lengths do not exceed the workspace. The results of our study demonstrated that the sliding mode controller have caused positive stretching influences on the stability of the system in spite of the chattering phenomenon even high speed, also it has a better performance 
comparing the resistant PID controller in many conditions and proving a suitable choice of their parameters.

\section{References}

[1] M. Zarebidoki, A. Lotfavar and H.R Fahham, "Dynamic Modeling and Adaptive Control of a Cablesuspended Robot", Proceedings of the World Congress on Engineering 2011, WCE 2011, London, U.K, vol. III, (2011).

[2] M. Ceccarelli, "Fundamentals of Mechanics of Robotic Manipulation", Intelligent Systems, Control and Automation: Science and Engineering Series, Springer, Dordrecht, vol. 27, (2004).

[3] D. Surdilovic, J. Zhang and R. Bernhard, "STRING-MAN: wire-robot technology for safe, flexible and human-friendly gait rehabilitation", Proc. of the ICORR International Conference, (2007), pp.446-453.

[4] A. B. Alp, and S. K. Agrawal, "Cable suspended robots: design, planning and control", in proceeding of international conference of robotics and automation, Washington, DC, (2002), pp. 4275-4280.

[5] Z. Shiler, S. Filter and S. Dubowski, "Time op-timal paths and acceleration lines of robotic manipulators", Proc. of the 26th Conf. Decision and Control, (1987), pp. 98-99.

[6] M. Ceccarelli, "Problems and Experiences on Cable Based Service Robots for Physiotherapy Applications", New Trends in Medical and Service Robots, vol. 16, (2013), pp. $27-42$.

[7] C. Avilacarrasco, E. Ottaviano, M. Ceccarelli and M. Toti, "Ca TraSys(CassinoTrakingSystèm), A Wire Systèm for Expremental Evalution of Robot Workspace", journal of robotics and mechatronics, vol.14, (2002),pp. 78-87.

[8] P. Gallina and R. L. Williams II, "Planar Cable-Direct-Driven Robots, Part I: Kinematics and Statics", 2001 ASME Design Technical Conferences 27th Design Automation Conference, Pittsburgh, PA, (2001).

[9] M. A. Khosravi and H. D. Taghirad, "Experimental performance of robust PID controller on a planar cable robot", Mechanisms and Machine Science, vol. 12, (2013), pp. 337-352.

[10] R. Saravana Kumar, "Sliding Mode Control of Induction Motor using Simulation Approach publied in IJCSNS", International Journal of Computer Science and Network Security, vol.9, no.10, (2010).

[11] K.D. Young, "A control engineer's guide to sliding mode control”, IEEE Transactions on Control Systems Technology, vol. 7, no. 3, (1999), pp.28-342.

[12] W. B. Gao and J.C.Hung, "Variable structure control of nonlinear systems: A new approach", IEEE Trans. Ind. Electron, (1993), pp. 45-55.

[13] M. A. Khosravi and H. D. Taghirad, "Experimental performance of robust PID controller on a planarcable robot", Mechanisms and Machine Science, vol. 12, (2013), pp. 337-352.

[14] F. Inel and 1. khochmane, "Comparison Performance between PID and PD Controllers for Cable Based Robots", World Journal of Engineering, vol. 2, no. 6, (2014).

[15] P. Gallina and R. L. Williams II, "Part II: dynamics and control", Proceedings of the 2001 ASME Design Technical Conferences 27th Design Automation Conference Pittsburgh PA, (2001), pp. 1-8.

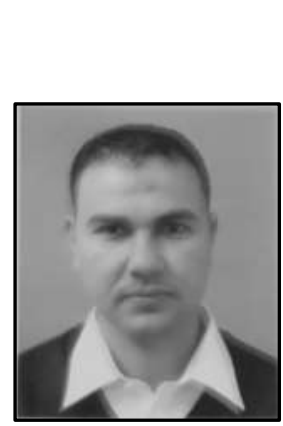

\section{Author}

Fouad Inel, he received his Engineer Degree in Mechanical Engineering, in 2005, and his Magister Degree in 2010 and his $\mathrm{PhD}$ in 2015, both in MECHATRONICS, from SKIKDA University, SKIKDA, Algeria. Now he is in the Department of technology, since 2010, his research interests is oriented robotic control. 
International Journal of Control and Automation

Vol. 11, No. 1 (2018) 